\title{
Dangerous hitchhikers? Evidence for potentially pathogenic Vibrio spp. on microplastic particles
}

\author{
Inga V. Kirstein ${ }^{\text {a, } *, 1}$, Sidika Kirmizi ${ }^{\text {a, }}{ }^{\text {, Antje Wichels }}{ }^{\text {a }}$, Alexa Garin-Fernandez ${ }^{\mathrm{a}}$, Rene Erler ${ }^{\mathrm{a}}$, Martin Löder ${ }^{\mathrm{a}, \mathrm{b}}$, \\ Gunnar Gerdts ${ }^{\text {a }}$ \\ a Department of Microbial Ecology, Biologische Anstalt Helgoland, Alfred Wegener Institute Helmholtz Centre for Polar and Marine Research, Helgoland, Germany \\ b Animal Ecology I, University of Bayreuth, NWI 5.0.01.43.1, Bayreuth, Germany
}

\section{A R T I C L E I N F O}

Article history:

Received 9 May 2016

Received in revised form 27 June 2016

Accepted 4 July 2016

Available online xxx

Keywords:

Synthetic polymers

Vector

Pathogens

North Sea

Baltic Sea

\section{A B S T R A C T}

The taxonomic composition of biofilms on marine microplastics is widely unknown. Recent sequencing results indicate that potentially pathogenic Vibrio spp. might be present on floating microplastics. Hence, these particles might function as vectors for the dispersal of pathogens. Microplastics and water samples collected in the North and Baltic Sea were subjected to selective enrichment for pathogenic Vibrio species. Bacterial colonies were isolated from CHROMagar ${ }^{\mathrm{TM}}$ Vibrio and assigned to Vibrio spp. on the species level by MALDI-TOF MS (Matrix Assisted Laser Desorption/Ionisation Time of Flight Mass Spectrometry). Respective polymers were identified by ATR FT-IR (Attenuated Total Reflectance Fourier Transform - Infrared Spectroscopy). We discovered potentially pathogenic Vibrio parahaemolyticus on a number of microplastic particles, e.g. polyethylene, polypropylene and polystyrene from North/Baltic Sea. This study confirms the indicated occurrence of potentially pathogenic bacteria on marine microplastics and highlights the urgent need for detailed biogeographical analyses of marine microplastics.

(C) 2016 Published by Elsevier Ltd.

\section{Introduction}

The production of synthetic polymers started over 100 years ago and meanwhile the worldwide production reached up to 311 million tons per year (PlasticsEurope, 2015). As a consequence of improper disposal synthetic polymers represent the most rapidly growing form of anthropogenic debris entering and accumulating in the oceans (Andrady, 2011; Thiel and Gutow, 2005).

Due to their durability most synthetic polymers are poorly degradable in the marine environment but become brittle and subsequently break down in small particles, so called microplastics (Andrady, 2011; Corcoran et al., 2009). Several size categorizations of plastics have been suggested by various researchers (Gregory and Andrady, 2003; Moore, 2008) while plastic fragments smaller than $5 \mathrm{~mm}$ are categorized as microplastics by Barnes et al. (2009). Once floating on seawater, plastic debris can be transported over long distances by wind, currents and wave action (Barnes et al., 2009).

As all surfaces in the marine environment microplastic is rapidly colonized by bacteria (Harrison et al., 2014) and subsequently by a plethora of organisms building up complex biofilms (Dobretsov, 2009). Harrison et al. (2014) detected bacterial colonization of low density polyethylene microplastics already after 7 days exposure in marine sediments. Also Lobelle and Cunliffe (2011) proved biofilm formation on plastics after 1 week of incubation in seawater via quantitative biofilm assays. Prior studies evidenced that even harmful al-

\footnotetext{
* Corresponding author.

Email address: inga.kirstein@awi.de (I.V. Kirstein)

1 These authors contributed equally to the manuscript.
}

gal species were detected in biofilms on plastic debris (Masó et al., 2003). Being highly heterogeneous environments, biofilms offer important ecological advantages such as the accumulation of nutrients, as protective barrier, for mechanical stability (Flemming, 2002) or the formation of micro-consortia of different species that orchestrate the degradation of complex substrates (Wimpenny, 2000).

Zettler et al. (2013) showed that microbial communities on marine plastic debris differ consistently from the surrounding seawater communities and coined the term "Plastisphere" for this habitat. Furthermore, Amaral-Zettler et al. (2015) reported that "Plastisphere" communities are genetically unique from the free marine water communities that envelop them and possess dominant taxa that are highly variable and diverse. Moreover, the composition of biofilm communities on plastic in marine habitats varies with season, geographical location and plastic substrate type (Oberbeckmann et al., 2014).

Zettler et al. (2013) have suggested that plastic particles may serve as vectors for the dispersal of human pathogens (Vibrio spp.). Using a culture-independent approach, the author's detected sequences affiliated to Vibrio spp. on marine plastic debris (Zettler et al., 2013), i.e. on plastic particles in the North Atlantic by using molecular tools (Amplicon Pyrotag Sequencing). Furthermore, De Tender et al. (2015) recently detected Vibrionaceae on marine plastics from the Belgian North Sea, by using next-generation amplicon sequencing. However, due to short read lengths, a conclusive identification on the species level was not provided so far (De Tender et al., 2015; Zettler et al., 2013).

Species of the genus Vibrio belong to the class Gammaproteobacteria and are highly abundant in sediments, estuaries and marine coastal waters (Barbieri et al., 1999). Vibrios are gram-negative, 
rod-shaped chemoorganotrophic and facultatively anaerobic organisms. Besides occurring free-living in aquatic environments, Vibrio spp. are known to colonize a variety of marine organisms, utilizing released nutrients on these living surfaces (Huq et al., 1983; Visick, 2009) or living in symbiosis (McFall-Ngai and Ruby, 1991; McFall-Ngai, 2002; McFall-Ngai and Ruby, 1998).

Some Vibrio species are known as animal pathogens invading coral species and causing coral bleaching (Ben-Haim et al., 2003) and others are classified as human pathogens causing serious infections (Morris, 2003). Especially Vibrio parahaemolyticus, Vibrio vulnificus and Vibrio cholerae are known as water-related human pathogens which cause wound infections associated with recreational bathing, septicemia or diarrhea after ingestion of contaminated foods (Thompson et al., 2004a).

Although Vibrio infections are common in tropical areas, the last decade showed a significant increase in documented cases also in European regions, such as in the Mediterranean Sea (Gras-Rouzet et al., 1996; Martinez-Urtaza et al., 2005) or in the more temperate Northern waters (Eiler et al., 2006). Prior studies reported that the number of Vibrio infections correspond closely with the sea surface temperature pointing to a possible link to climate change related phenomena (e.g. global warming, heat waves) (Baker-Austin et al., 2010, 2012).

Böer et al. (2013) reported that Vibrio alginolyticus, V. parahaemolyticus, $V$. vulnificus and $V$. cholerae occurred in water and sediments in the central Wadden Sea and in the estuaries of the rivers Ems and Weser. The most prevalent species were $V$. alginolyticus followed by $V$. parahaemolyticus, $V$. vulnificus and $V$. cholera (Böer et al., 2013), reflecting earlier findings on the composition of Vibrio communities in other parts of the North Sea (Bauer et al., 2006; Collin and Rehnstam-Holm, 2011; Hervio-Heath et al., 2002; Schets et al., 2011). While $V$. vulnificus and $V$. cholerae were detected mainly in the Baltic Sea, V. parahaemolyticus occurred as the main potential pathogenic Vibrio spp. in the North Sea (Böer et al., 2013; Oberbeckmann et al., 2011b; Ruppert et al., 2004; Schets et al., 2010).

As already mentioned most synthetic polymers are poorly degradable and are rapidly colonized by microorganisms. Microplastics could be transported over long distances in marine environments, as compared to naturally occurring polymers, and therefore function as a vector for the dispersal of harmful or even human pathogenic species. To verify or falsify the occurrence of potentially pathogenic Vibrio spp. on marine plastics, we analysed plastics and corresponding water samples of the North and Baltic Sea with respect to potentially human pathogenic Vibrio spp. by using cultivation-dependent methods (alkaline peptone water (APW), CHROMagar ${ }^{\mathrm{TM} V}$ Vibrio), followed by state of the art identification of bacteria on the species level by MALDI-TOF MS (Erler et al., 2015). The main focus of the study was on detecting the main potentially human pathogenic species $V$. cholerae, V. parahaemolyticus and $V$. vulnificus. Polymers were identified by ATR FT-IR (Attenuated Total Reflectance Fourier Transform - Infrared Spectroscopy).

\section{Materials and methods}

\subsection{Sampling}

To detect Vibrio spp. attached to microplastics, neustonic particles were collected during two research cruises in 2013 and 2014 at 62 sampling stations in the North and Baltic Sea (see Table A1). Neuston samples were taken with a Neuston Catamaran equipped with a $300 \mu \mathrm{m}$ net. The Catamaran was towed alongside the vessel for about 30-45 min per station. The volume passing the Neuston net was recorded by use of a mechanical flowmeter (Table A2). Further samples were taken at the drift line of the south port beach at the island Helgoland at low tide in August 2013 (station 63). Particles recovered in the cod end of the Neuston net or sampled at the drift line of Helgoland were sorted by stereo microscopy and using a Bogoroff chamber and finally transferred to Petri dishes containing sterile seawater. Single particles identified visually according to the definition by Barnes et al. (2009) in a size range of $0.5-5 \mathrm{~mm}$ and to colour and texture as being synthetic polymers were picked with sterile forceps and washed three times with $10 \mathrm{ml}$ of sterile seawater, to remove loosely attached organisms.

For comparison of microplastic-attached and waterborne Vibrio spp., additional surface seawater samples were taken on both research cruises with a thoroughly flushed bucket or rosette sampler (SBE 911 plus, Sea-Bird Electronics, US) and a maximal volume of 11 was filtered onto $0.45 \mu \mathrm{m}$ sterile membrane filters (Sartorius stedim biotech, US). Environmental parameters (temperature, salinity) were recorded by a ship-based thermosalinograph (SBE 21SeaCAT, Sea-Bird Electronics, US) or by the sensors of the rosette sampler. The temperature of Helgoland was measured manually with a thermometer and the salinity was recorded with a salinometer (Autosal, GUILDLINE, Canada) (Table A3).

\subsection{Enrichment \& isolation of Vibrio spp.}

All particles and membrane filters (seawater samples) were immediately transferred individually into sterile glass tubes with alkaline peptone water $(15 \mathrm{ml} \mathrm{APW})$ and incubated in a rotating incubator at $37^{\circ} \mathrm{C}$ for $48 \mathrm{~h}$ in the dark for the growth of a broad spectrum of mesophilic and potentially pathogenic Vibrio spp., enabling their selective enrichment.

After APW incubation the tubes were visually checked for growth and turbid samples were plated by using an inoculation loop or Spiral-plater (easySpiral ${ }^{\circledR}$ Dilute; Interscience, France) on selective CHROMagar ${ }^{\mathrm{TM} V}$ Vibrio (MAST Diagnostica GmbH, Germany) (Di Pinto et al., 2011). All inoculated CHROMagar ${ }^{\mathrm{TM} V}$ Vibrio were incubated at $37^{\circ} \mathrm{C}$ for $24 \mathrm{~h}$ in the dark. The appearing colonies were checked with respect to distinct colony colorations typical for $V$. parahaemolyticus, V. vulnificus and $V$. cholerae according to the manufacturers' instruction. Representative colonies for each coloration were picked and differentially streaked out on marine broth agar (Oppenheimer and ZoBell, 1952) with reduced salinity $(\mathrm{MB}-50 \%=16 \mathrm{PSU})$. Incubation was performed at $37^{\circ} \mathrm{C}$ for $24 \mathrm{~h}$ in the dark.

Even though CHROMagar TMVibrio is a selective medium for the isolation of $V$. cholerae, $V$. vulnificus and $V$. parahaemolyticus, other species have the ability to grow on these media appearing with the same colony colorations. For instance, Vibrio fluvialis occurred in mauve coloured colonies distinct from $V$. parahaemolyticus and Vibrio mimicus in turquoise coloured colonies distinct for $V$. vulnificus and $V$. cholerae. Hence for a conclusive identification all presumptive $V$. cholerae, $V$. vulnificus and $V$. parahaemolyticus strains were further analysed by MALDI-TOF MS.

\subsection{MALDI-TOF MS}

For MALDI-TOF analysis, all isolates were grown overnight on MB- $50 \%$ agar plates as described above. To create high quality mass spectra, proteins of the strains isolated during the cruise in 2013 were extracted using a previously described formic acid/acetonitrile extraction method (Mellmann et al., 2008). For fast identification, all other strains (cruise 2014 and Helgoland samples 2013) were analysed via the direct transfer procedure according to manufacturers' recommendations (Bruker Daltonics Inc., Germany, Bremen). This involved 
picking colonies after $24 \mathrm{~h}$ of cultivation with sterile toothpicks and directly transferring onto the MALDI-TOF MS target plate (MSP 96 target polished steel) as thin layer. Each sample spot was first overlaid with $1 \mu \mathrm{l}$ formic acid $(70 \% \mathrm{v} / \mathrm{v})$ followed by an overlay with $1 \mu \mathrm{lma}-$ trix solution (saturated solution of $\alpha$-cyano-4-hydroxycinnamic acid in $50 \%$ acetonitrile and $2.5 \%$ trifluoroacetic acid) and directly screened. All spectra were acquired using the microflex LT/SH system (Bruker Daltonics Inc., Germany, Bremen). Species identification was done by using the Biotyper ${ }^{\mathrm{TM}}$ software (version 3.1 ) according to the manufacturer's instructions, where 70 most prominent mass peaks were compared to the mass spectra of the Bruker library as well as the "VibrioBase" library (Erler et al., 2015).

In order to check the reliability of the species assignment via MALDI-TOF MS all $V$. cholerae, $V$. vulnificus and $V$. parahaemolyticus were verified by PCR amplification of species-specific genes and additionally screened for virulence-associated genes (section 2.4).

\subsection{PCR of regulatory and virulence-related genes}

As described previously (Oberbeckmann et al., 2011a), DNA extraction of Vibrio strains identified by MALDI-TOF MS was carried out using lysozyme/SDS lysis and phenol/chloroform extraction, followed by isopropanol precipitation. Prior to PCR experiments, DNA quantity and quality was determined photometrically (TECAN infinite M200, Switzerland). Species-specific PCR for toxR genes was performed with all $V$. parahaemolyticus, $V$. vulnificus and $V$. cholerae strains respectively using the universal forward primer Utox $F$ together with the species specific primers VptoxR, VvtoxR and VctoxR, respectively (Bauer and Rorvik, 2007; Di Pinto et al., 2005). Specific PCRs targeting thermostable direct haemolysin $(t d h)$ (Nishibuchi and Kaper, 1985 ) and the $t d h$ related haemolysin (trh) (Honda et al., 1991; Honda and Iida, 1993) genes were performed with the primer sets $t d h D 3 F /$ tdhD1R and trhFR2/trhRR6 to strains assigned to $V$. parahaemolyticus (Bauer and Rorvik, 2007; Tada et al., 1992). To test $V$. cholerae strains for the presence of a unique chromosomal region indicating the serotypes O139 (Albert et al., 1997) and O1 (Hoshino et al., 1998) and the cholera toxin gene $c t x A$ (Singh et al., 2002) a multiplex PCR was performed with the primer sets $O 139 F / O 139 R, O 1 F / O 1 R$ and ctxA1/ctxA2 (Bauer and Rorvik, 2007; Mantri et al., 2006; Nandi et al., 2000). All reactions were performed in duplicate. In case of discordant results, a third PCR was carried out. The PCRs were performed as described by Böer et al. (2013) with the exception that $20 \mathrm{ng}$ of template DNA was used. The following reference strains were used as positive controls: V. vulnificus ATCC 27562 (VvtoxR) (The Federal Institute for Risk Assessment, BfR), V. parahaemolyticus RIMD 2210633 (VptoxR; tdh) (German Collection of Microorganisms and Cell Cultures, DSMZ), V. parahaemolyticus CM12 (tdh; trh), V. parahaemolyticus CM24 (trh) (provided by Carsten Matz, HZI), V. cholerae CH 111 (VctoxR; O1), V. cholerae CH 187 (VctoxR; O139; ctxA) and V. cholerae CH 258 (VctoxR; ctxA; O1) (BfR). Vibrio harveyi ATCC 25919 (DSMZ) was used as negative control in each PCR. PCR products were confirmed to be of the expected size by a MultiNA Microchip electrophoresis system (MCE-202 MultiNA, Shimadzu Biotech).

\subsection{FT-IR analyses of particles}

After incubation in APW, all particles were rinsed using deionized water and dried at $60{ }^{\circ} \mathrm{C}$ overnight. Prior to analysis, particles were rinsed with ethanol $(70 \% \mathrm{v} / \mathrm{v})$ and the surface was scraped with a scalpel to avoid organic contamination interfering with FT-IR analysis. The FT-IR spectra of particles were recorded by the attenuated to- tal reflectance (ATR) technique using a Tensor 27 spectrometer with a Platinum ATR unit (Bruker, Germany). For each analysis 16 scans in the range $4000-400 \mathrm{~cm}^{-1}$ with a resolution of $4 \mathrm{~cm}^{-1}$ and $6 \mathrm{~mm}$ aperture were performed and averaged. The obtained IR spectra were compared to reference-spectra of an in-house database covering $143 \mathrm{spec}$ tra of different synthetic polymers and the IR Library from Bruker Optics containing 350 entries. Spectra processing and database comparisons were performed by using OPUS 7.2. (Bruker, Germany).

\section{Results}

\subsection{Occurrence and characterization of microplastics}

Particles were collected from 39 stations in the North Sea and 5 stations in the Baltic Sea. In total, 170 particles were collected in the North Sea and 15 particles in the Baltic Sea, mostly abundant at stations $17,56,58$ and 61 , with $\geq 10$ particles from each station, respectively (Table A4). Almost all particles showed signs of weathering, including cracks and pitting. Most particles were covered at least partially with dense biofilms on their surface, indicating colonization by various biota. Polymer identification of presumptive synthetic polymer particles, (ATR FT-IR (Table A3)) confirmed 141 as synthetic polymers, 14 particles were non-plastics such as chitin or keratin, and 30 could not be further identified. All of the 15 presumptive microplastics of Helgoland drift line were identified as synthetic polymers. The most abundant synthetic polymer throughout all sampling sites was polyethylene, comprising over $40 \%$ of the collected particles at all sites. Polypropylene and polystyrene were also frequently found at all sites, representing $14-20 \%$ and $5-7 \%$ of all particles, respectively (Fig. 1).

\subsection{Identification and geographic distribution of Vibrio spp. in water samples}

Water samples were taken from all stations in the North and Baltic Sea with the exception of Helgoland drift line (station 63) resulting in 326 APW enrichment cultures. Out of these, 323 displayed growth and were subjected to further isolation of bacteria on selective CHROMagarTMVibrio agar plates, with respect to $V$. cholerae, $V$. vulnificus and $V$. parahaemolyticus.

From all water samples, 151 pure cultures of representative mauve and turquoise blue colonies were grown on marine broth agar and subjected to MALDI-TOF MS. Out of these, 104 were identified as Vibrio spp. by MALDI-TOF MS.

With the exception of three isolates, all Vibrio water strains could be identified by MALDI-TOF MS on a conclusive species level. We identified $38 \%$ out of all Vibrio water isolates (104) as V. parahaemolyticus, $16 \%$ as $V$. vulnificus and $11 \%$ as $V$. cholerae. Further on, $21 \%$ of the strains were classified as $V$. fluvialis, $7 \%$ as $V$. mimicus, $5 \%$ as Vibrio diazotrophicus, $1 \%$ as Vibrio metschnikovii (Table A6).

A single $V$. parahaemolyticus strain (VN-4212) isolated from water (station 3) carried the virulence-associated gene $t d h$, while $t r h$ was not detected in any strain (Table A6). No $V$. cholerae strain belonged to the $O 1 / O 139$ type or carried the $c t x A$ gene.

In general, $V$. parahaemolyticus was detected only in North Sea waters (Fig. 2) in a temperature range of $14.9-21.1^{\circ} \mathrm{C}$ and at salinities between 16.9 and 32.4 PSU (Table A3). The potentially pathogenic species $V$. cholerae, $V$. vulnificus and $V$. parahaemolyticus occurred mainly in coastal and estuarine regions of the North Sea. Vib- 

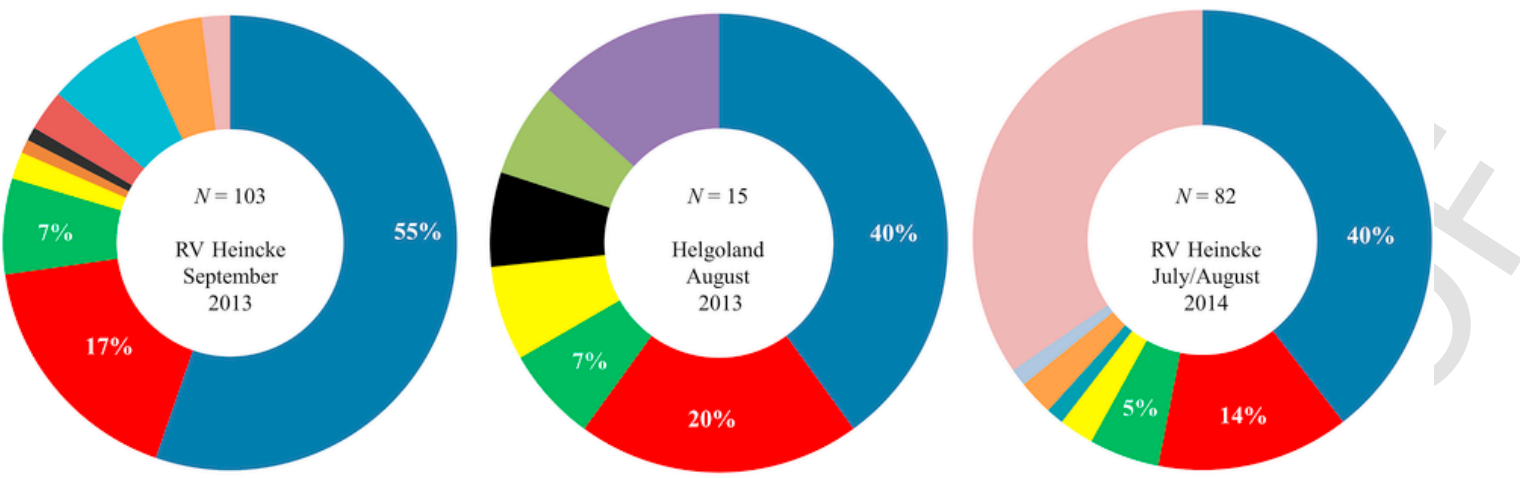

@ Polyethylene
= Acrylnitril-Butadien-Styrole
= Polyurethane
@ Stearic Acid

- Polypropylene
= Polyvinyl alcohol
= Polvenylchloride
= Not Identified

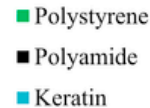

= Varnish

= Ethylene vinyl alcohol

m Chitin

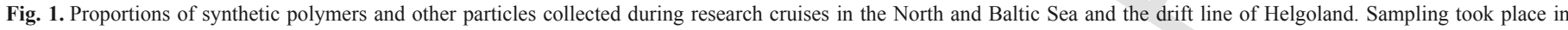

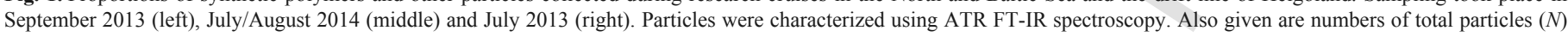
and percentages of polyethylene, polypropylene and polystyrene particles.

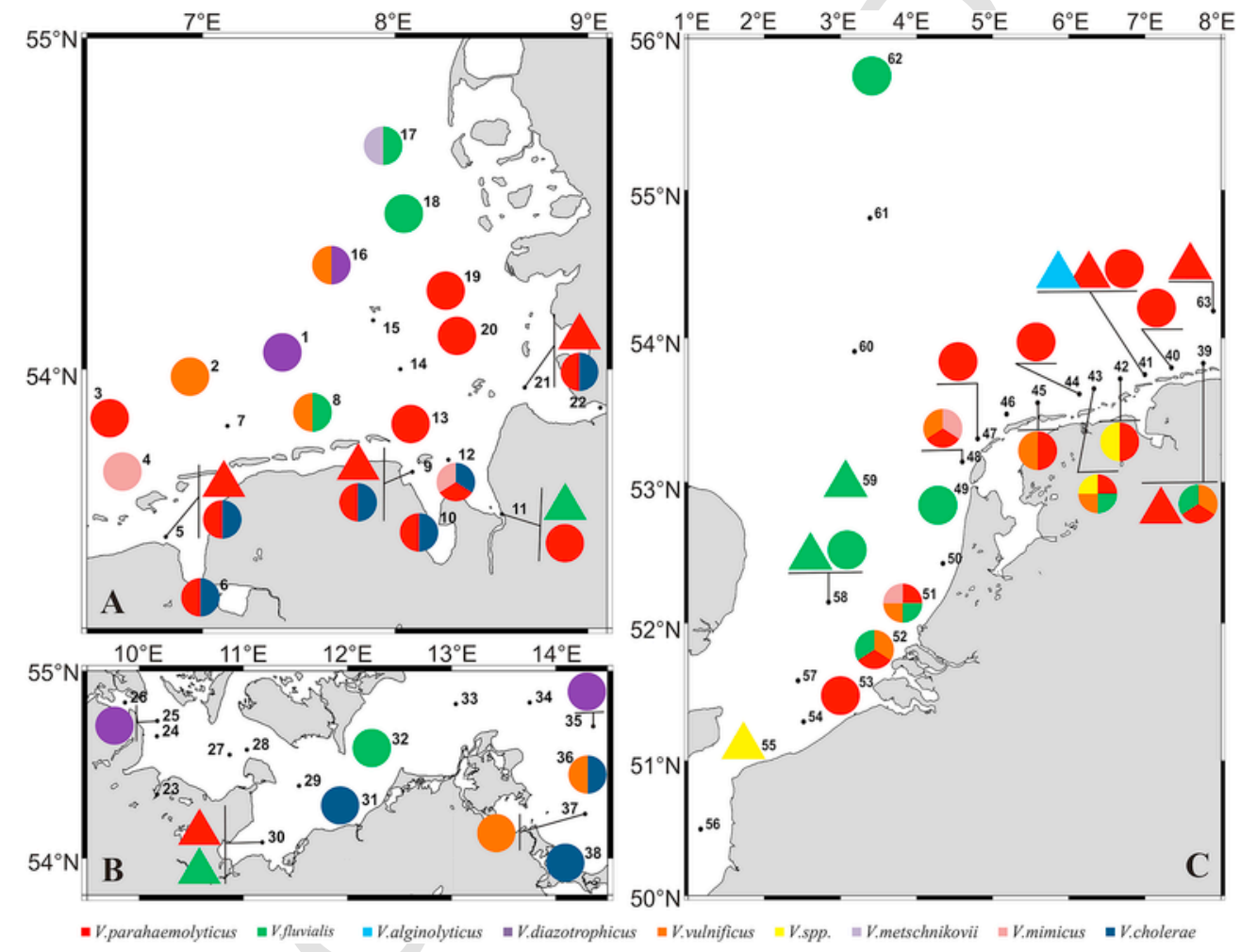

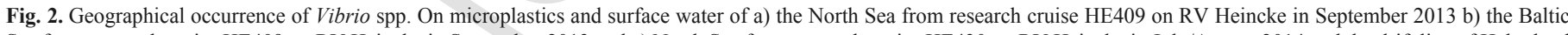

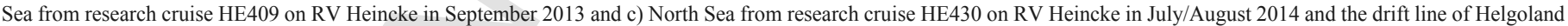
(station 63). (O) species detected from surrounding seawater $(\triangle)$ species detected on microplastic particles.

rio fluvialis was the only species that was detected in open waters in the North Sea (Fig. 2 a, c).

In the Baltic Sea both species, $V$ vulnificus and $V$. cholerae appeared close to the Polish border at $14.5-14.9{ }^{\circ} \mathrm{C}$ and 5.7-7.3 PSU (station 36, 37, 38). $V$. cholerae occurred also nearby to Rostock at $14.1^{\circ} \mathrm{C}$ and 11.7 PSU (station 31) (Fig. 2 b; Table A3). Vibrio fluvialis was detected once in Baltic surface water inside Germany and Denmark (station 32).

\subsection{Identification and geographic distribution of Vibrio spp. on microplastics}

All collected particles of North Sea, Baltic Sea and Helgoland drift line were subjected to selective APW enrichment resulting in 200 APW cultures. Out of these 161 displayed growth and were processed as described previously. From 15 microplastic particles from the North and Baltic Sea, in total 37 putative (according to the 
colony colorations) $V$. cholerae, $V$. vulnificus or $V$. parahaemolyticus strains were isolated. At the drift line of Helgoland 4 putative $V$. parahaemolyticus strains from 4 different microplastic particles were isolated. Of these 41 strains, 22 were identified as Vibrio spp. by MALDI-TOF MS. Thirteen strains were identified as $V$. parahaemolyticus (59\%), six as $V$. fluvialis (27\%) and one as $V$. alginolyticus (5\%) (Table A5). Even though we isolated representative coloured colonies neither $V$. vulnificus nor $V$. cholerae could be detected on microplastic particles.

$V$. parahaemolyticus was isolated from three polyethylene fibres and four polyethylene fragments during the cruises in the North Sea at temperatures between 14.8 and $21.1^{\circ} \mathrm{C}$ and salinities between 12.6 and 32.4 PSU (Table A3). These were collected in the Ems estuary (station 5), near the uninhabited island Mellum (station 9), the Elbe estuary (station 21), and close to the Frisian islands (stations 39 and 41) (Fig. 2a, c). Additionally V. parahaemolyticus was isolated from two polyethylene films and two polypropylene fragments of Helgoland drift line at a water temperature of $16.6^{\circ} \mathrm{C}$ and a salinity of $30.2 \mathrm{PSU}$ (station 63) (Fig. 2c). V. fluvialis was detected on four non-identified particles collected between the UK and the Netherlands (stations 58, 59) and on a polyethylene fragment of the Weser estuary (Germany, station 11). V. alginolyticus was detected on one polyethylene fragment close to the Frisian island Juist (station 41). In the English Channel (station 55) an unspecified Vibrio spp. was detected on a polyethylene fragment (Fig. 2c).

One polypropylene film (station 30; Fig. 2b) collected close to the coastal regions of Wismar in the Baltic Sea at $14.8{ }^{\circ} \mathrm{C}$ and 12.6 PSU (Table A3) was colonized by both species, $V$. parahaemolyticus and $V$. fluvialis. Vibrio parahaemolyticus was detected only once on this single microplastic particle in the Baltic Sea (Fig. 2b).

\section{Discussion}

Although the microbial colonization of marine plastic particles was reported already in the 1970s, (Carpenter et al., 1972; Carpenter and Smith Jr., 1972) this issue received increasing attention in the last years due to the discovery of the large oceanic garbage patches (Kaiser, 2010; Ryan, 2014) and the general perception of microplastics being an emerging environmental topic of concern. In this context, it was also hypothesized, that microplastics may function as a vector for dispersion of invasive species including toxic algae but also pathogenic organisms (Masó et al., 2003; Zettler et al., 2013).

Recently the microbial community on marine plastics was targeted in several studies, highlighting the composition and diversity of plastic-attached microorganisms (Carson et al., 2013; Zettler et al., 2013; Oberbeckmann et al., 2014; Reisser et al., 2014; Amaral-Zettler et al., 2015; De Tender et al., 2015). Within the microbial community on the "Plastisphere" (Zettler et al., 2013) sequences related to the genus Vibrio, a group of bacteria also containing serious pathogens, were found (De Tender et al., 2015; Zettler et al., 2013). However, in both studies a conclusive identification on the species level could not be provided so far due to the usage of next-generation amplicon sequencing and the short read lengths inherent to the methodology.

In our study we were able to prove the presence of potentially pathogenic $V$. parahaemolyticus on twelve floating microplastics for the first time by a selective cultivation approach and identification on species level by MALDI-TOF MS.

\subsection{Microplastics in the North and Baltic Sea}

In the present study, we observed more microplastic particles in North Sea waters compared to the Baltic Sea. Up to now, information on the abundance of microplastics in coastal waters of the North and Baltic Sea is scarce, and a comparison of the findings is problematic due to missing standard operational procedures (SOP) for sampling, extraction and analysis of microplastics (Löder and Gerdts, 2015).

During both cruises in 2013 and 2014, 77\% of all collected and identified microplastics as well as all collected microplastics at the drift line of Helgoland, occurred as fragments with rough and uneven edges clearly indicating a breakdown of larger plastics (Thompson et al., 2004). Brittleness of particles including cracks and pitting could be detected on collected microplastics which might be the result of degradation processes or wind and wave actions (Andrady and Neal, 2009). Thus it could be suggested that most of the collected microplastics were exposed long enough to the marine environment to get brittle and be transported over long distances. Thiel et al. (2011) reported hotspots of accumulating microplastics in the North Sea and a rapid transport through the German Bight due to strong westerly winds. In contrast, based on the relationship between litter accumulation on Helgoland beaches and southerly winds, Vauk and Schrey (1987) suggested that these winds might push anthropogenic debris from source regions which results in accumulation on local beaches. Galgani et al. (2000) proposed that the predominant northward currents in the eastern part of the German Bight transport floating debris and accumulate it in an area to the west of Denmark. However due to the focus of our study (Vibrio spp.), these findings should be interpreted with care since we were not aiming at monitoring microplastics explicitly and in a systematic way.

By far the majority of microplastics from the North and Baltic Sea as well as from the Helgoland drift line was identified as polyethylene, followed by polypropylene and polystyrene (Fig. 1). Prior studies already reported high portions of these three polymers in the course of various samplings in marine and coastal environments which mirrors our results (Browne et al., 2010; Moret-Ferguson et al., 2010; Oberbeckmann et al., 2014) and furthermore reflect the usage of these polymers in the worldwide economy. In the United States polyethylene, polystyrene, polypropylene and polyethylene terephthalate are the most widely produced and disposed synthetic polymers (Barnes et al., 2009). In Europe polyethylene and polypropylene are the synthetic polymers with the highest demand in various application segments, especially in packaging (PlasticsEurope, 2015).

\subsection{Vibrio hitchhikers}

Biofilm communities on environmental plastic samples were recently characterized in several studies applying molecular tools. The diverse microbial communities on marine plastic debris differed clearly from the surrounding seawater (Zettler et al., 2013; Oberbeckmann et al., 2014; Amaral-Zettler et al., 2015; De Tender et al., 2015).

The herein described presence of potentially human pathogenic Vibrio spp. on microplastics has to be discussed in the light of these latter studies. The first indication of the presence of Vibrio spp. on marine microplastics was published by Zettler et al. (2013), who reported the dominance of this genus that constituted nearly $24 \%$ of the whole biofilm community on a single polypropylene particle collected from the North Atlantic. In 2015, De Tender et al. (2015) reported the detection of members of the family Vibrionaceae on marine plastics from the Belgian North Sea. Recently a review of 
Keswani et al. (2016) highlights the lack of knowledge about the persistence of potentially pathogenic Vibrio spp. on plastic debris. Our study clearly confirmed the presence of cultivable Vibrio spp. on $13 \%$ of all marine collected microplastic particles. Amongst others, potentially pathogenic $V$. parahaemolyticus strains were detected on $12 \mathrm{mi}-$ croplastic particles. Only collected polyethylene, polypropylene and polystyrene fragments were colonized by Vibrio spp.

In general Vibrio spp. tends to colonize marine biotic surfaces like corals or zooplankton/phytoplankton surfaces. V. cholerae strains, both $O 1$ and non-Ol serovars, as well as $V$. parahaemolyticus strains were found to be attached to the surfaces of copepods in natural waters (Huq et al., 1983). In comparison to naturally occurring polymers like chitin, synthetic polymers are poorly degradable and could therefore function as a mechanism for the transport and persistence of Vibrio species. Pruzzo et al. (2008) reviewed substrate-specificity of $V$. cholerae on the naturally occurring polymer chitin. They reported close interactions between $V$. cholerae and chitin surfaces in the environment including cell metabolic and physiological responses e.g. chemotaxis, cell multiplication, biofilm formation, and pathogenicity. With respect to plastic microbial communities, Oberbeckmann et al. (2014) found that the structure and taxonomic composition of these plastic associated communities vary with plastic type, but also with geographical location and season. Moreover, Amaral-Zettler et al. (2015) found that "Plastisphere" communities of the Atlantic and Pacific Ocean clustered more by geography than by polymer type, with exception of polystyrene that showed significant differences to polyethylene and polypropylene.

The substrate specificity of Vibrio spp. on synthetic polymers is still not investigated. However, since polyethylene, polypropylene, polystyrene and polyethylene terephthalate are the most widely disposed synthetic polymers globally (Barnes et al., 2009), it can be supposed that our results are biased due to the high accumulation of these specific synthetic polymers in our oceans.

Potentially pathogenic $V$. parahaemolyticus as well as $V$. fluvialis occurred in water as well as on microplastic particles. Recent studies report that $V$. parahaemolyticus and $V$. alginolyticus are prevailing inhabitants of North Sea waters (Böer et al., 2013; Oberbeckmann et al., 2011b). In contrast, $V$. vulnificus and $V$. cholerae are more abundant in the Baltic Sea (Böer et al., 2012), which is also reflected by our findings. As already shown elsewhere, free-living bacterial communities in general differ significantly from plastic-attached ones (Amaral-Zettler et al., 2015; De Tender et al., 2015; Oberbeckmann et al., 2014; Zettler et al., 2013), which holds also for microplastics investigated here. With respect to potentially pathogenic Vibrio spp., the species $V$. vulnificus and $V$. cholerae were only isolated from seawater samples but not identified on microplastics in the framework of our study. In contrast, $V$. parahaemolyticus was detected in both, water and on microplastic particles (Fig. 2). Additionally, V. parahaemolyticus was detected once in the Baltic Sea and only on a microplastic particle throughout the entire cruise.

Plastic is a persistent material and may serve as a reservoir and vector for potentially pathogenic microorganisms. The drift of potentially harmful algae species, barnacles and bryozoans on plastic debris (Barnes, 2002; Masó et al., 2003) is already well documented. Our results fuel the evidence for potentially pathogenic bacteria being dispersed on microplastic particles by wind or currents. However, although we identified $V$. parahaemolyticus on microplastics to species level, due to the high intra-species diversity information on the geographical origin of these hitchhikers or the microplastics is not possible, since the assignment of Vibrio species down to specific ecotypes was not successful.

Vibrio spp. on microplastics were detected mainly close to the coast and only occasionally offshore. However, microplastics and seawater samples carrying $V$. parahaemolyticus were located exclusively in estuarine and coastal areas of the North and Baltic Sea. $V$. parahaemolyticus occurrences in seawater were already addressed in several studies in Northern European waters (Bauer et al., 2006; Böer et al., 2013; Collin and Rehnstam-Holm, 2011; Ellingsen et al., 2008; Lhafi and Kühne, 2007; Oberbeckmann et al., 2011b; Schets et al., 2011; Schets et al., 2010). Environmental parameters, such as temperature, salinity or plankton abundance have an effect on $\mathrm{Vib}$ rio spp. communities and abundances (Blackwell and Oliver, 2008; Caburlotto et al., 2010; Drake et al., 2007; Martinez-Urtaza et al., 2008; Thompson et al., 2004b; Turner et al., 2009; Vezzulli et al., 2009). Vezzulli et al. (2010) and Schets et al. (2010) identified seawater temperature as a key factor influencing the presence of $\mathrm{Vib}$ rio spp., for instance it is well documented that $V$. parahaemolyticus favours warmer water temperatures (Sobrinho et al., 2010). Recently, pathogenic $V$. parahaemolyticus was detected even in temperate European waters (Baker-Austin et al., 2010; Martinez-Urtaza et al., 2005). Martinez-Urtaza et al. (2008) observed higher occurrence of this taxon during periods of lower salinity and in general this taxon was primarily detected in areas of reduced salinity close to freshwater discharge runoff, which is also in agreement with our findings.

In our study $V$. parahaemolyticus occurred also on microplastics collected from the drift line at Helgoland. Oberbeckmann et al. (2011b) detected $V$. parahaemolyticus during summer months and reported that the abundance of Vibrio spp. was influenced by specific environmental conditions like the decrease in salinity due to an inflow of coastal water at Helgoland Roads (North Sea, Germany). Each Vibrio group was influenced by different combinations of environmental parameters but no single environmental parameter could explain the whole community structure of $V$. alginolyticus and $V$. parahaemolyticus populations in the German Bight (Oberbeckmann et al., 2011b). The authors also reported that free-living and plankton-attached $\mathrm{Vib}$ rio spp. abundances were mainly driven by the same environmental parameters (Oberbeckmann et al., 2011b). This suggests that the potentially pathogenic V. parahaemolyticus detected both on North Sea microplastics and in seawater samples of one station were influenced equally by environmental conditions.

\section{Conclusion}

This study successfully evidences the occurrence of potentially pathogenic Vibrio spp. on the species level on marine microplastics by use of MALDI-TOF MS for the first time. In most of the cases, these species co-occurred also in surrounding seawater, suggesting that seawater serves as a possible source for Vibrio colonization on microplastics. The fact that we for the first time detected $V$. parahaemolyticus exclusively on polyethylene, polypropylene and polystyrene particles, points to the urgent need to further address the biogeography and persistence of these hitchhikers on marine microplastics. Studies on the co-occurrence of specific $V$. parahaemolyticus genotypes on microplastic and surface water from the North Sea are particularly important specifically with reference to the potential health impacts of microplastic-colonizing microbial assemblages.

\section{Acknowledgments}

We would like to thank the team of the RV Heincke (AWI) for technical support. The authors thank also for the modified maps provided by Dr. Mirco Scharfe (AWI, Helgoland).

This work was partially founded by the Alfred Wegener Institute for Polar and Marine Research. We thank for the support of MikrOMIK a SWL/PAKT project by the Leibniz Association 
(SAW-2014-IOW-2). We thank three anonymous reviewers for their helpful comments.

\section{Appendix A. Supplementary data}

Supplementary data related to this article can be found at http://dx. doi.org/10.1016/j.marenvres.2016.07.004.

\section{Uncited reference}

Webb et al., 2009.

\section{References}

Albert, M.J., Islam, D., Nahar, S., Qadri, F., Falklind, S., Weintraub, A., 1997. Rapid detection of Vibrio cholerae O139 Bengal from stool specimens by PCR. J. Clin. Microbiol. 35, 1633-1635.

Amaral-Zettler, L.A., Zettler, E.R., Slikas, B., Boyd, G.D., Melvin, D.W., Morrall, C.E., Proskurowski, G., Mincer, T.J., 2015. The biogeography of the Plastisphere: implications for policy. Front. Ecol. Environ. 13, 541-546.

Andrady, A.L., 2011. Microplastics in the marine environment. Mar. Pollut. Bull. 62, 1596-1605.

Andrady, A.L., Neal, M.A., 2009. Applications and societal benefits of plastics. Philosophical Trans. R. Soc. B Biol. Sci. 364, 1977-1984.

Baker-Austin, C., Stockley, L., Rangdale, R., Martinez-Urtaza, J., 2010. Environmental occurrence and clinical impact of Vibrio vulnificus and Vibrio parahaemolyticus: a European perspective. Environ. Microbiol. Rep. 2, 7-18.

Baker-Austin, C., Trinanes, J., Taylor, N.G.H., Hartnell, R., Siitonen, A., Martinez-Urtaza, J., 2012. Emerging Vibrio risk at high latitudes in response to ocean warming. Nat. Clim. Change 3, 73-77.

Barbieri, E., Falzano, L., Fiorentini, C., Pianetti, A., Baffone, W., Fabbri, A., Matarrese, P., Casiere, A., Katouli, M., Kühn, I., Möllby, R., Bruscolini, F., Donelli, G., 1999. Occurrence, diversity, and pathogenicity of halophilic Vibrio spp. and Non-O1 Vibrio cholerae from estuarine waters along the Italian Adriatic coast. Appl. Environ. Microbiol. 65, 2748-2753.

Barnes, D.K., 2002. Biodiversity: invasions by marine life on plastic debris. Nature 416, 808-809.

Barnes, D.K., Galgani, F., Thompson, R.C., Barlaz, M., 2009. Accumulation and fragmentation of plastic debris in global environments. Philosophical transactions of the Royal Society of London. Series B. Biol. Sci. 364, 1985-1998.

Bauer, A., Østensvik, , Florvåg, M., Ørmen, , Rørvik, L.M., 2006. Occurrence of Vibrio parahaemolyticus, V. cholerae, and V. vulnificus in Norwegian blue mussels (Mytilus edulis). Appl. Environ. Microbiol. 72, 3058-3061.

Bauer, A., Rorvik, L.M., 2007. A novel multiplex PCR for the identification of Vibrio parahaemolyticus, Vibrio cholerae and Vibrio vulnificus. Lett. Appl. Microbiol. 45, 371-375.

Ben-Haim, Y., Thompson, F.L., Thompson, C.C., Cnockaert, M.C., Hoste, B., Swings, J., Rosenberg, E., 2003. Vibrio coralliilyticus sp. nov., a temperature-dependent pathogen of the coral Pocillopora damicornis. Int. J. Syst. Evol. Microbiol. 53, 309-315.

Blackwell, K., Oliver, J., 2008. The ecology of Vibrio vulnificus, Vibrio cholerae and Vibrio parahaemolyticus in North Carolina Estuaries. J. Microbiol. 46, 146-153.

Böer, S., Hauk, G., Duty, O., Luden, K., Heinemeyer, E.-A., Brennholt, N., 2012. Pathogenic Vibrio species in German coastal waters of the North sea and the Baltic sea - a comparison. In: International Symposium "Pathogenic Vibrio spp. in Northern European Waters", 36.

Böer, S., Heinemeyer, E.-A., Luden, K., Erler, R., Gerdts, G., Janssen, F., Brennholt, N., 2013. Temporal and spatial distribution patterns of potentially pathogenic Vibrio spp. at recreational beaches of the German North Sea. Microb. Ecol. 65, 1052-1067.

Browne, M.A., Galloway, T., Thompson, R.C., 2010. Spatial patterns of plastic debris along Estuarine shorelines. Environ. Sci. Technol. 44, 3404-3409.

Caburlotto, G., Haley, B.J., Lleò, M.M., Huq, A., Colwell, R.R., 2010. Serodiversity and ecological distribution of Vibrio parahaemolyticus in the venetian Lagoon, Northeast Italy. Environ. Microbiol. Rep. 2, 151-157.

Carpenter, E.J., Anderson, S.J., Harvey, G.R., Miklas, H.P., Peck, B.B., 1972. Polystyrene spherules in coastal waters. Science 178, 749-750.

Carpenter, E.J., Smith Jr., K.L., 1972. Plastics on the Sargasso sea surface. Science $175,1240-1241$.

Carson, H.S., Nerheim, M.S., Carroll, K.A., Eriksen, M., 2013. The plastic-associated microorganisms of the North Pacific Gyre. Mar. Pollut. Bull. 75, 126-132.

Collin, B., Rehnstam-Holm, A.-S., 2011. Occurrence and potential pathogenesis of Vibrio cholerae, Vibrio parahaemolyticus and Vibrio vulnificus on the South Coast of Sweden. FEMS Microbiol. Ecol. 78, 306-313.
Corcoran, P.L., Biesinger, M.C., Grifi, M., 2009. Plastics and beaches: a degrading relationship. Mar. Pollut. Bull. 58, 80-84.

De Tender, C.A., Devriese, L.I., Haegeman, A., Maes, S., Ruttink, T., Dawyndt, P., 2015. Bacterial community profiling of plastic litter in the Belgian part of the North sea. Environ. Sci. Technol. 49, 9629-9638.

Di Pinto, A., Ciccarese, G., Tantillo, G., Catalano, D., Forte, V.T., 2005. A collagenase-targeted multiplex PCR assay for identification of Vibrio alginolyticus, Vibrio cholerae, and Vibrio parahaemolyticus. J. Food Prot. ${ }^{\circledR} 68,150-153$.

Di Pinto, A., Terio, V., Novello, L., Tantillo, G., 2011. Comparison between thiosulphate-citrate-bile salt sucrose (TCBS) agar and CHROMagar Vibrio for isolating Vibrio parahaemolyticus. Food Control. 22, 124-127.

Dobretsov, S., 2009. Marine biofilms. In: Dürr, S., Thomason, J.C. (Eds.), Biofouling Wiley-Blackwell, Oxford, UK, http://dx.doi.org/10.1002/9781444315462.ch9.

Drake, S.L., DePaola, A., Jaykus, L.A., 2007. An overview of Vibrio vulnificus and Vibrio parahaemolyticus. Compr. Rev. Food Sci. Food Saf. 6, 120-144.

Eiler, A., Johansson, M., Bertilsson, S., 2006. Environmental influences on Vibrio populations in northern temperate and boreal coastal waters (Baltic and Skagerrak Seas). Appl. Environ. Microbiol. 72, 6004-6011.

Ellingsen, A.B., Jorgensen, H., Wagley, S., Monshaugen, M., Rorvik, L.M., 2008. Genetic diversity among Norwegian Vibrio parahaemolyticus. J. Appl. Microbiol. 105, 2195-2202.

Erler, R., Wichels, A., Heinemeyer, E.A., Hauk, G., Hippelein, M., Reyes, N.T., Gerdts, G., 2015. VibrioBase: a MALDI-TOF MS database for fast identification of Vibrio spp. that are potentially pathogenic in humans. Syst. Appl. Microbiol. 38, 16-25.

Flemming, H.C., 2002. Biofouling in water systems - cases, causes and countermeasures. Appl. Microbiol. Biotechnol. 59, 629-640.

Galgani, F., Leaute, J.P., Moguedet, P., Souplet, A., Verin, Y., Carpentier, A., Goraguer, H., Latrouite, D., Andral, B., Cadiou, Y., Mahe, J.C., Poulard, J.C., Nerisson, P., 2000. Litter on the sea floor along European coasts. Mar. Pollut. Bull. 40, 516-527.

Gras-Rouzet, S., Donnio, P.Y., Juguet, F., Plessis, P., Minet, J., Avril, J.L., 1996. First European case of gastroenteritis and bacteremia due toVibrio hollisae. Eur. J. Clin. Microbiol. Infect. Dis. 15, 864-866.

Gregory, M.R., Andrady, A.L., 2003. Plastics in the marine environment. Plast. Environ. $379-401$.

Harrison, J.P., Schratzberger, M., Sapp, M., Osborn, A.M., 2014. Rapid bacterial colonization of low-density polyethylene in coastal sediment microcosms. BMC Microbiol. 14 (1), 232.

Hervio-Heath, D., Colwell, R.R., Derrien, A., Robert-Pillot, A., Fournier, J.M., Pommepuy, M., 2002. Occurrence of pathogenic vibrios in coastal areas of France. J. Appl. Microbiol. 92, 1123-1135.

Honda, T., Abad-Lapuebla, M.A., Ni, Y., Yamamoto, K., Miwatani, T., 1991. Characterization of a new thermostable direct haemolysin produced by a Kanagawa-phenomenon-negative clinical isolate of Vibrio parahaemolyticus. J. General Microbiol. 137, 253-259.

Honda, T., Iida, T., 1993. The pathogenicity of Vibrio parahaemolyticus and the role of the thermostable direct haemolysin and related haemolysins. Rev. Med. Microbiol. 4, 106-113.

Huq, A., Small, E.B., West, P.A., Huq, M.I., Rahman, R., Colwell, R.R., 1983. Ecological relationships between Vibrio cholerae and planktonic crustacean copepods. Appl. Environ. Microbiol. 45, 275-283.

Kaiser, J., 2010. The dirt on ocean garbage patches. Science 328. 1506-1506.

Hoshino, K., Yamasaki, S., Mukhopadhyay, A. K., Chakraborty, S., Basu, A., Bhattacharya, S. K., Nair, G.B., Shimada, T., Takeda, Y., 1998. Development and evaluation of a multiplex PCR assay for rapid detection of toxigenic Vibrio cholerae $\mathrm{O} 1$ and O139. FEMS Immunol. Med. Microbiol. 20.

Keswani, A., Oliver, D.M., Gutierrez, T., Quilliam, R.S., 2016. Microbial hitchhikers on marine plastic debris: human exposure risks at bathing waters and beach environments. Mar. Environ. Res. 118, 10-19.

Lhafi, S.K., Kühne, M., 2007. Occurrence of Vibrio spp. in blue mussels (Mytilus edulis) from the German Wadden sea. Int. J. Food Microbiol. 116, 297-300.

Lobelle, D., Cunliffe, M., 2011. Early microbial biofilm formation on marine plastic debris. Mar. Pollut. Bull. 62, 197-200.

Löder, M.J., Gerdts, G., 2015. Methodology used for the detection and identification of microplastics - a Critical Appraisal. In: Bergmann, M., Gutow, L., Klages, M. (Eds.), Marine Anthropogenic Litter. Springer International Publishing, pp. 201-227.

Mantri, C.K., Mohapatra, S.S., Ramamurthy, T., Ghosh, R., Colwell, R.R., Singh, D.V., 2006. Septaplex PCR assay for rapid identification of Vibrio cholerae including detection of virulence and int SXT genes. FEMS Microbiol. Lett. 265, 208-214.

Martinez-Urtaza, J., Lozano-Leon, A., Varela-Pet, J., Trinanes, J., Pazos, Y., Garcia-Martin, O., 2008. Environmental determinants of the occurrence and distribution of Vibrio parahaemolyticus in the rias of Galicia, Spain. Appl. Environ. Microbiol. 74, 265-274.

Martinez-Urtaza, J., Simental, L., Velasco, D., DePaola, A., Ishibashi, M., Nakaguchi, Y., Nishibuchi, M., Carrera-Flores, D., Rey-Alvarez, C., Pousa, A., 2005. Pan- 
demic Vibrio parahaemolyticus O3:K6, Europe. Emerg. Infect. Dis. $11,1319-1320$.

Masó, M., Garcés, E., Pagès, F., Camp, J., 2003. Drifting plastic debris as a potential vector for dispersing Harmful Algal Bloom (HAB) species. Sci. Mar. 67, 107-111.

McFall-Ngai, M., Ruby, E.G., 1991. Symbiont recognition and subsequent morphogenesis as early events in an animal-bacterial mutualism. Science 254, 1491-1494.

McFall-Ngai, M.J., 2002. Unseen forces: the influence of bacteria on animal development. Dev. Biol. 1-14.

McFall-Ngai, M.J., Ruby, E.G., 1998. Sepiolids and vibrios: when first they meet. BioScience 48, 257-265.

Mellmann, A., Cloud, J., Maier, T., Keckevoet, U., Ramminger, I., Iwen, P., Dunn, J., Hall, G., Wilson, D., Lasala, P., Kostrzewa, M., Harmsen, D., 2008. Evaluation of matrix-assisted laser desorption ionization-time-of-flight mass spectrometry in comparison to 16S rRNA gene sequencing for species identification of nonfermenting bacteria. J. Clin. Microbiol. 46, 1946-1954.

Moore, C.J., 2008. Synthetic polymers in the marine environment: a rapidly increasing, long-term threat. Environ. Res. 108, 131-139.

Moret-Ferguson, S., Law, K.L., Proskurowski, G., Murphy, E.K., Peacock, E.E., Reddy, C.M., 2010. The size, mass, and composition of plastic debris in the western North Atlantic Ocean. Mar. Pollut. Bull. 60, 1873-1878.

Morris, J.J.G., 2003. Cholera and other types of vibriosis: a story of human pandemics and oysters on the half shell. Clin. Infect. Dis. 37, 272-280.

Nandi, B., Nandy, R.K., Mukhopadhyay, S., Nair, G.B., Shimada, T., Ghose, A.C., 2000. Rapid method for species-specific identification ofVibrio cholerae using primers targeted to the gene of outer membrane protein OmpW. J. Clin. Microbiol. 38, 4145-4151.

Nishibuchi, M., Kaper, J.B., 1985. Nucleotide sequence of the thermostable direct hemolysin gene of Vibrio parahaemolyticus. J. Bacteriol. 162, 558-564.

Oberbeckmann, S., Loeder, M.G., Gerdts, G., Osborn, A.M., 2014. Spatial and seasonal variation in diversity and structure of microbial biofilms on marine plastics in Northern European waters. FEMS Microbiol. Ecol. 90, 478-492.

Oberbeckmann, S., Wichels, A., Maier, T., Kostrzewa, M., Raffelberg, S., Gerdts, G., 2011a. A polyphasic approach for the differentiation of environmental Vibrio isolates from temperate waters. FEMS Microbiol. Ecol. 75, 145-162.

Oberbeckmann, S., Wichels, A., Wiltshire, K., Gerdts, G., 2011b. Occurrence of Vibrio parahaemolyticus and Vibrio alginolyticus in the German Bight over a seasonal cycle. Ant. Van Leeuwenhoek 100, 291-307.

Oppenheimer, C.H., ZoBell, C.E., 1952. The growth and viability of sixty three species of marine bacteria influenced by hydrostatic pressure. J. Mar. Res. 11, 10-18.

PlasticsEurope, 2015. Plastics - the Facts 2015. An Analysis of European Plastics Production, Demand and Waste Data.

Pruzzo, C., Vezzulli, L., Colwell, R.R., 2008. Global impact of Vibrio cholerae interactions with chitin. Environ. Microbiol. 10, 1400-1410.

Reisser, J., Shaw, J., Hallegreaff, G., Proietti, M., Barnes, D.K., Thums, M., Wilcox, C., Hardesty, B.D., Pattiaratchi, C., 2014. Millimeter-sized marine plastics: a new Pelagic habitat for microorganisms and invertebrates. PLoS One 9.

Ruppert, J., Panzig, B., Guertler, L., Hinz, P., Schwesinger, G., Felix, S., Friesecke, S., 2004. Two cases of severe sepsis due to Vibrio vulnificus wound infection acquired in the Baltic Sea. Eur. J. Clin. Microbiol. Infect. Dis. 23, 912-915.

Ryan, P.G., 2014. Litter survey detects the South Atlantic 'garbage patch'. Mar. Pollut. Bull. 79, 220-224.

Schets, F.M., van den Berg, H.H.J.L., Marchese, A., Garbom, S., de Roda Husman, A.M., 2011. Potentially human pathogenic vibrios in marine and fresh bathing wa- ters related to environmental conditions and disease outcome. Int. J. Hyg. Environ. Health 214, 399-406.

Schets, F.M., van den Berg, H.H.J.L., Rutjes, S.A., de Roda Husman, A.M., 2010. Pathogenic Vibrio species in Dutch shellfish destined for direct human consumption. J. Food Prot. 73 (4), 734-738.

Singh, D.V., Isac, S.R., Colwell, R.R., 2002. Development of a hexaplex PCR assay for rapid detection of virulence and regulatory genes in Vibrio cholerae and Vibrio mimicus. J. Clin. Microbiol. 40 (11), 4321-4324.

Sobrinho, P.D.C., Destro, M.T., Franco, B., Landgraf, M., 2010. Correlation between environmental factors and prevalence of Vibrio parahaemolyticus in oysters harvested in the southern coastal area of Sao Paulo State, Brazil. Appl. Environ. Microbiol. 76, 1290-1293.

Tada, J., Ohashi, T., Nishimura, N., Shirasaki, Y., Ozaki, H., Fukushima, S., Takano, J., Nishibuchi, M., Takeda, Y., 1992. Detection of the thermostable direct hemolysin gene (tdh) and the thermostable direct hemolysin-related hemolysin gene (trh) of Vibrio parahaemolyticus by polymerase chain reaction. Mol. Cell. Probes 6, 477-487.

Thiel, M., Gutow, L., 2005. The ecology of rafting in the marine environment. II. The rafting organisms and community. Oceanogr. Mar. Biol. 43, 279-418.

Thiel, M., Hinojosa, I.A., Joschko, T., Gutow, L., 2011. Spatio-temporal distribution of floating objects in the German Bight (North Sea). J. Sea Res. 65, 368-379.

Thompson, F.L., Iida, T., Swings, J., 2004a. Biodiversity of vibrios. Microbiol. Mol. Biol. Rev. 68, 403-431.

Thompson, J.R., Randa, M.A., Marcelino, L.A., Tomita-Mitchell, A., Lim, E., Polz, M.F., 2004b. Diversity and dynamics of a North Atlantic coastal Vibrio community. Appl. Environ. Microbiol. 70, 4103-4110.

Thompson, R.C., Olsen, Y., Mitchell, R.P., Davis, A., Rowland, S.J., John, A.W.G., McGonigle, D., Russell, A.E., 2004. Lost at sea: where is all the plastic?. Science 304,838 .

Turner, J.W., Good, B., Cole, D., Lipp, E.K., 2009. Plankton composition and environmental factors contribute to Vibrio seasonality. Isme J. 3, 1082-1092.

Vauk, G.J.M., Schrey, E., 1987. Litter pollution from ships in the German Bight. Mar. Pollut. Bull. 18, 316-319.

Vezzulli, L., Pezzati, E., Moreno, M., Fabiano, M., Pane, L., Pruzzo, C., 2009. Benthic ecology of Vibrio spp. and pathogenic Vibrio species in a coastal Mediterranean environment (La Spezia Gulf, Italy). Microb. Ecol. 58, 808-818.

Vezzulli, L., Previati, M., Pruzzo, C., Marchese, A., Bourne, D.G., Cerrano, C., the VibrioSea, C., 2010. Vibrio infections triggering mass mortality events in a warming Mediterranean Sea. Environ. Microbiol. 12, 2007-2019.

Visick, K.L., 2009. An intricate network of regulators controls biofilm formation and colonization by Vibrio fischeri. Mol. Microbiol. 74, 782-789.

H.K., Crawford, R.J., Sawabe, T., Ivanova, E.P., 2009. Poly(ethylene terephthalate) polymer surfaces as a substrate for bacterial attachment and biofilm formation. Microbes Environ. 24, 39-42.

Wimpenny, J., 2000. An overview of biofilms as functional communities. In: Allison, D.G., Gilbert, P., Lappin-Scott, H.M., Wilson, M. (Eds.), Community Structure and Co-operation in Biofilms. Cambridge University Press, Cambridge, United Kingdom, pp. 1-24.

Zettler, E.R., Mincer, T.J., Amaral-Zettler, L.A., 2013. Life in the 'Plastisphere': microbial communities on plastic marine debris. Environ. Sci. Technol. 47 (13), $7137-7146$. 